Stuttgart, Jena, Lübeck, Ulm: Gustav Fischer Verlag 1997.

[2] IMS Research Group, IMS America, Ambler, Pennsylvania USA 1979.

[3] Tätigkeitsbericht 1991 des Bundesgesundheitsamtes, München: MMV Medizin Verlag 1992.

[4] Tätigkeitsbericht 1992 des Bundesgesundheitsamtes, München: MMV Medizin Verlag 1993.

[5] Tätigkeitsbericht 1993 des Bundesgesundheitsamtes, München: MMV Medizin Verlag 1994.

[6] Tätigkeitsbericht 1994 des Robert Koch-Instituts, München: MMV Medizin Verlag 1995.

[7] Tätigkeitsbericht 1995 des Robert Koch-Instituts, München: MMV Medizin Verlag 1996.

[8] Melchert, H.-U.: Einnahme von Psychopharmaka. In: Bellach, B.-M. (Hrsg.): Die Gesundheit der Deutschen. Robert Koch-Institut, Berlin 1995.

[9] Melchert, H.-U., und Linopf, H.: Daten der Nationalen Untersuchungs-Surveys zum Verbrauch oraler Kontrazeptiva (OC) in
West- und Ostdeutschland. In: Bellach, B.-M (Hrsg.): Die Gesundheit der Deutschen. Robert Koch-Institut 1996.

[10] Melchert, H.-U., Görsch, B., und Hoffmeister, H.: Nichtstationäre Arzneimittelanwendung und subjektive Arzneimittelverträglichkeit in der bundesdeurschen Wohnbevölke rung der 25-69jährigen - Ergebnisse der Erhebung des ersten Nationalen UntersuchungsSurveys 1984-1986. RKI-Schrift 1/95, München: MMV Medizin Verlag 1995.

[11] Krause-Girth, C.: Schein-Lösungen - Die Verschreibungspraxis von Psychopharmaka Bonn: Psychiatrie-Verlag 1989.

[12] Deutsche Hauptstelle gegen die Suchtgefahren (Hrsg.): Medikamentenabhängigkeit Freiburg im Breisgau: Lambertus-Verlag 1992.

[13] Knopf, H., Braemer-Hauth, M., Melchert, H.-U., und Thefeld, W.: Ergebnisse der Nationalen Untersuchungs-Surveys zum Laxanzienverbrauch, Bundesgesundhbl. 38 12 (1995) 459-467.

[14] Melchert, H.-U, and Pabel, E.: The Tocopherol Pattern in Human Serum Is Markedly Influenced by Intake of Vitamin E-
Drugs - Results of the German National Health Surveys - Journal of the American Oil Chemists Society 75, 2 (1998) 213-216.

[15] Melchert, H.-U., Knopf, H., and Gerding, B.: Coffeine concentration in Human serum in Dependence o Medication, Coffee consumption and Socieodemographic Variables - Results of the German National Health surveys - Pharmacoepidemiology and Drug Safety 7 Suppl. 2 (1998) 121.

[16] Melchert, H.-IJ., Knopf, H., and Pabel, E.: Use of Acetylsalicylic Acid-containing Drugs in Germany: Serum Levels of Salicylic Acid in Participants of National and Regional Surveys. Pharmacoepidemiology and Drug Safety 7 Suppl.2 (1998) 202-203.

[17] Kleinebrecht, J., Fränz, J, und Windorfer, A. Arzneimittel in der Schwangerschaft und Stillzeit. Stuttgart: Wissenschaftliche Verlagsgesellschaft 1995.

Anschrifr der Verfasser:

Dr. Hildtraud Knopf, Dr. Hans-Ulrich Melchert, Robert Koch-Institut, Postfach 6502 80, 13302 Berlin

\title{
Schützt Stillen vor atopischem Ekzem?
}

Grulee und Sandford [1] veröffentlichten 1936 eine Beobachtung an über 20000 Säuglingen, die bei Ernährung mit abgekochter Kuhmilch etwa sieben mal so häufig ein Ekzem in den ersten neun Lebensmonaten entwickelten wie ausschließlich gestillte Kinder. Allerdings hatten die Autoren damals alle Hauteffloreszenzen, außer dem Kopfgneis, als Ekzem bezeichnet. Stillen wird seither als wirksame Präventionsmaßnahme gegen Ekzem (Neurodermitis, Milchschorf) empfohlen. Dies ist durchaus berechtigt angesichts der beeindruckenden immunologischen Eigenschaften von Muttermilch [2]. Die klinischen und epidemiologischen Beobachtungen, die nach der Pionierarbeit von Grulee und Sanford [1] publiziert wurden, waren allerdings nicht so eindeutig, wie die Theorie es erwarten ließ. Kramer

Tabelle 1: Prozentanteil der Mütter, die ihr Kind sechs Monate oder länger gestillt haben in Anhängigkeit von der Sozialschicht nach Winkler et al. [6]. Nach Daten der multizentrischen Allergiestudie MAS-90 [4]

\begin{tabular}{cccc}
\hline $\begin{array}{c}\text { Untere } \\
\text { Schicht }\end{array}$ & $\begin{array}{c}\text { Mittlere } \\
\text { Schicht }\end{array}$ & $\begin{array}{c}\text { Obere } \\
\text { Schicht }\end{array}$ & $\mathrm{p}$ \\
\hline 11 & 24 & 36 & 0.00000 \\
\hline
\end{tabular}

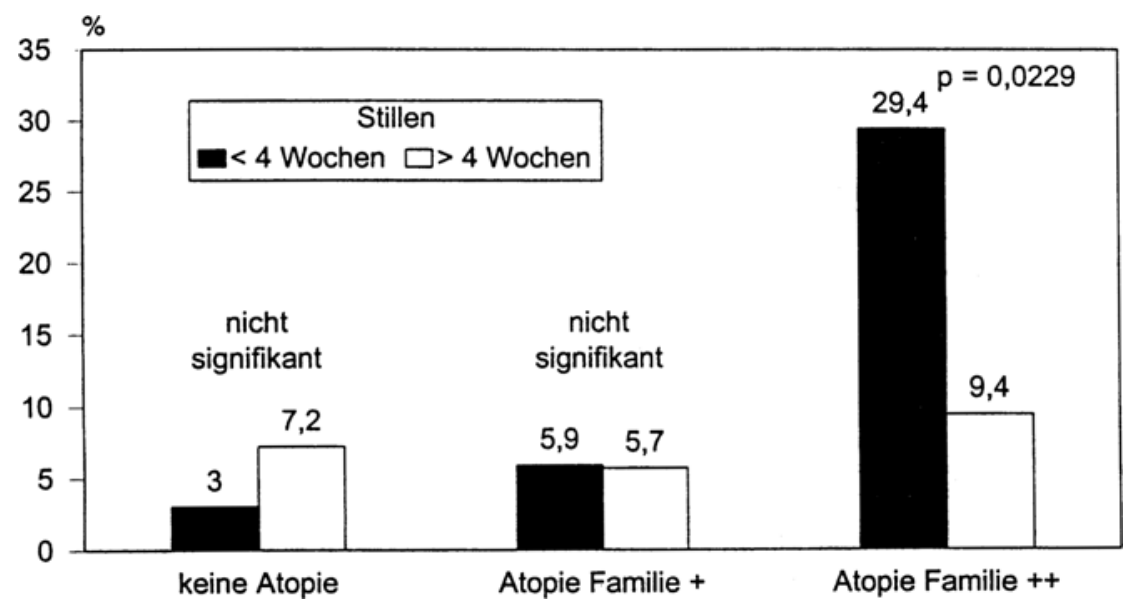

Abbildung 1: Prävalenz der Atopischen Dermatitis (A. D.) im Altersintervall ein bis drei Monate in Abhängigkeit von der Familienanamnese bei Säuglingen, die unter oder über vier Wochen gestillt worden waren. Atopie Familie + bzw. ++: Ein Atopiker bzw. mindestens zwei Atopiker in der engen Familie.

[3] fügte deshalb der Überschrift seiner Metaanalyse aller Publikationen zu diesem Thema hinzu: "Das goldenene Jubiläum einer Kontroverse«.

Warum konnten die einen Forschergruppen den präventiven Effekt des
Stillens gegen Neurodermitis bestätigen und die anderen nicht? Alle Beobachtungen hatten ihre Schwächen. Aber allen gemeinsam war, daß sie keine randomisierte Zuordnung der Probanden zum Stillen oder zu einer Flaschennahrung durchführen konn- 
ten. Der Entschluß und die Fähigkeit zu stillen, ließen sich nicht randomisieren.

Mütter sind über die Erblichkeit der Neurodermitis informiert, Säuglinge mit einer atopischen Familienanamnese werden häufiger und länger gestillt [4] Außerdem ist die Neurodermitis ebenso wie das Stillen mit dem Bildungsstand assoziiert [4] (s. auch Tab. 1). Ursachen und Wirkungen lassen sich in epidemiologischen Studien schwer entwirren, und so fanden wir auch in der multizentrischen Allergiestudie (MAS-90) keinen Unterschied in der Ekzemhäufigkeit von Säuglingen, die unter drei Monaten zu solchen, die mindestens drei Monate oder gar über sechs Monate hinaus ausschließlich gestillt worden waren. Verglich man aber Säuglinge mi zwei atopischen Familienangehörigen, die bereits in den ersten vier Wochen abgestillt worden waren (als noch kein Ekzem aufgetreten war, das die Stillentscheidung hätte beeinflussen können) mit denjenigen, die in diesem Zeitraum ausschließlich Muttermilch erhalten hatten, dann war die Ekzemhäufigkeit in der nachfolgenden Periode bei den gestillten signifikant niedriger (Abb. 1). War das Ekzem erst einmal aufgetreten, dann wurde weitergestillt und der beobachtete Zusammenhang ging in die andere Richtung.

Die einzige Studie, in der eine randomisierte Zuordnung zu Frauenmilch oder einer anderen Ernährungsform gelungen war, wurde an Frühgeborenen durchgeführt: Lucas et al. [5] fanden bei denjenigen Frühgeborenen mit atopischer Familienanamnese eine geringere Ekzemprävalenz, die mit Frauenmilch genährt wurden, verglichen mit denen, die andere Flaschennahrung erhalten hatten.

Es bleibt also dabei: Stillen schützt vor Ekzem, auch wenn wir es nicht beobachten können oder sogar einen gegenläufigen Trend finden. Stillen sollten wir allerdings nicht nur bei atopischer Familienanamnese, sondern allen Kindern empfehlen.
Literatur:

[1] Grulee, C. G., and Sanford, H. N.: The influence of breast and artificial feeding on infantile eczema. J. Pediatr. 9 (1936) 223-225.

[2] Schroten, H.: Immunologische Aspekte bei der Ernährung mit Muttermilch. Monatsschr. Kinderheilkd. 142 (1994) 985-992.

[3] Kramer, M. S.: Does breast feeding help protect against atopic disease? Biology, methodo$\operatorname{logy}$, and a golden jubilee of controversy. J. Pediatr. 112 (1988) 181-190.

[4] Bergmann, R. L., Dudenhausen, J. W., Bergmann, E., Bergmann, K. E., Schmidt, E. Bauer, C. P., Dorsch, W., Forster, J., und Wahn, U.: Wie werden Säuglinge in Deutschland ernährt? Monatsschr. Kinderheilkd. 142 (1994) 412-417.

[5] Lucas, A., Brooke, O. G., Morley, R., Cole, T.J., and Bamford, M. F.: Early diet of preterm infants and development of allergic or atopic disease: randomized prospective study. Brit. Med. J. 300 (1990) 837-840.

[6] Winkler, J: Die Messung des sozialen Status mit Hilfe eines Index in den Gesundheitssurveys der DHP (Scaling social status in the German National Health Surveys). In Ahrens, W., Bellach, B., und Jökel, K. H.(Hrsg): Messung soziodemographischer Merkmale in der Epidemiologie. RKI-Schriften, MMV München, 1998, 69-74.

Renate L. Bergmann, Dr. Günther Edenharter, Prof. Dr. Karl-E. Bergmann, Robert Koch-Institut

\section{Arbeitskreis Lebensmittelchemischer Sachverständiger der Länder und des BgVV}

Der Arbeitskreis Lebensmittelchemischer Sachverständiger der Länder und des Bundesinstituts für gesundheitlichen Verbraucherschutz und Veterinärmedizin (BgVV) hat auf seiner 71. Sitzung am 24. und 25. März 1998 in Karlsruhe beschlossen, folgende Stellungnahme zu veröffentlichen:

\section{ALS-Stellungnahme zum Nachweis gentechnisch verän- derter Lebensmittel mittels molekularbiologischer Methoden}

1. Für eine vergleichbare Analytik sollten alle amtlichen Untersuchungseinrichtungen die gleichen Primerpaare verwenden.

Es ist daher erforderlich, daß vor der Erarbeitung von geeigneten Nachweisverfahren ausreichend Informationen über die veränderten Sequenzen zugänglich sind, um geeignete Primerpaare (zwei und mehr, wenn es sinnvoll erscheint) auswählen zu können.

2. Für einen gesicherten Nachweis, mit dem gerichtsfest festgestellt wird, daß ein gentechnisch verändertes Lebensmittel vorliegt, sollen folgende Verfahrensparameter zugrunde gelegt werden:

- Mehrfachbestimmung (mindestens zwei Aufarbeitungen aus einer Probe mit anschließender PCR),

- Vorgehensweise bei inhomogenem Material: mindestens $100 \mathrm{~g}$ Probenmaterial werden homogenisiert,

- die DNA-Extraktion erfolgt so, daß DNA in ausreichender Qualität vorliegt und inhibierende Faktoren soweit wie erforderlich ausgeschlossen werden,

- für einen gesicherten Nachweis sind PCR-Primer zu verwenden, mit de- nen Sequenzen aus den Übergangsbereichen von Strukturgenen zu Regulations-, Marker- oder Vektorgenen amplifiziert werden,

- die DNA-Menge, die für die PCR eingesetzt wird, sollte i. d. R. nicht unter $1 \mathrm{ng}$ liegen (üblich sind 5-50 ng),

- die PCR sollte 50 Zyklen keinesfalls überschreiten,

- eine Verifizierung des Amplifikats erfolgt durch Hybridisierung, Sequenzierung oder mindestens zwei Restriktionsenzymanalysen.

3. Notwendigkeit von authentischem Vergleichsmaterial

In der Regel sind gerichtsverwertbare Aussagen über positive Nachweise nur möglich, wenn authentisches Vergleichsmaterial zur Verifizierung der Methode vorliegt. In allen anderen Fällen ist nur von cinem Verdacht zu sprechen. 